\title{
ANALISIS BIAYA TRANSAKSI JAGUNG HIBRIDA DI PROVINSI GORONTALO
}

\author{
Mad Alfin A. Mohamad, Dwidjono Hadi Darwanto, Soeratno, Slamet Hartono \\ Pemerintah Daerah Gorontalo, Universitas Gadjah Mada, Universitas Gadjah Mada \\ E-mail : bri_exp@yahoo.com
}

\begin{abstract}
This study aims to count the transaction costs on farms of hybrid corn of dry seeds and analyze the factors that the transaction costs affect on farms of hybrid corn of dry seeds at through UPJ. This research was conducted in the Gorontalo province with samples in Gorontalo disctrict and Boalemo and using ekononometric equation analysis as a method of analysis. The results showed that the value of the average transaction costs on farm of hybrid corn of dry seed sales amounted to Rp1.545.466,per transaction on per farming, and the factors that affect significantly the fault tolerance of 5 percent to the transaction cost on farms of hybrid corn of dry seeds sales consist of the total production, regional market prices, technical labor wages, commissions and degradation rate. The conclusions in this study stated that the total transaction costs incurred the hybrid maize of dry seeds farmers on sales is still high enough to reduce farm income and the factors that the transaction cost affect on sales of hybrid corn of dry seeds significantly includes the total production, regional market prices, technical labor wages, commissions and degradation rate.
\end{abstract}

Keywords : Hybrid corn, transaction cost.

\begin{abstract}
Abstrak: Penelitian ini bertujuan untuk menghitung biaya transaksi usahatani jagung hibrida pipilan kering dan menganalisis faktor-faktor yang mempengaruhi biaya transaksi usahatani jagung hibrida pipilan kering melalui penjualan ke UPJ. Penelitian ini dilakukan di Provinsi Gorontalo dengan sampel kabupaten Gorontalo dan kabupaten Boalemo dengan menggunakan analisis persamaan ekononometrika sebagai metode analisisnya. Hasil penelitian menunjukkan bahwa besaran biaya transaksi ratarata penjualan jagung hibrida pipilan kering sebesar Rp1.545.466,- per transaksi per usahatani, serta terdapat faktor-faktor yang mempengaruhi secara signifikan pada toleransi kesalahan 5 persen terhadap biaya transaksi penjualan jagung pipilan kering yang meliputi total produksi, harga pasar regional, upah tenaga teknis, komisi dan nilai degradasi. Kesimpulan dalam penelitian ini menyatakan bahwa total biaya transaksi yang dikeluarkan petani atas penjualan jagung pipilan kering masih cukup tinggi sehingga memperkecil pendapatan usahatani jagung hibrida, serta faktor-faktor yang mempengaruhi biaya transaksi penjualan jagung hibrida pipilan kering secara signifikan meliputi total produksi, harga pasar regional, upah tenaga teknis, komisi dan nilai degradasi.
\end{abstract}

Kata kunci : Jagung hibrida, biaya transaksi.

\section{PENDAHULUAN}

Jagung merupakan komoditas unggulan di provinsi Gorontalo dan di dukung oleh pemerintah daerah melalui kebijakan program pengembangan daerah sentra komoditas jagung. Usahatani jagung hibrida mulai dikembangkan di Propinsi Gorontalo sejak tahun 2003 dengan pola kelembagaan antara petani dengan Unit Pelayanan Jasa (UPJ) sebagai unit usaha yang ditunjuk pemerintah daerah untuk melakukan kemitraan usaha dengan petani dalam bentuk penyertaan modal input faktor produksi usahatani. 
Widodo (2008) menjelaskan bahwa usahatani sebagai hasil kegiatan yang dapat dipengaruhi beberapa faktor alam, tenaga kerja, dan modal serta adanya peranan faktor alam yang jauh lebih besar dibandingkan usaha di sektor lain. Sedangkan Mubyarto (1972) mendefinisikan lembaga sebagai suatu organisasi atau kaidah-kaidah baik formal ataupun informal yang mengatur perilaku anggota masyarakat tertentu baik dalam kegiatan sehari-hari ataupun dalam usahanya untuk mencapai tujuan tertentu.

Penelitian ini memberikan referensi bagi petani dalam manajemenisasi usahatani atas biaya transaksi yang di keluarkannya. Untuk pemerintah daerah, penelitian ini menjadi bahan kajian untuk kebijakan standarisai biaya transaksi panjualan jagung pipilan kering demi keberlanjutan usahatani jagung hibrida di provinsi Gorontalo.

Penelitian ini bertujuan untuk menghitung biaya transaksi penjualan jagung pipilan kering per transaksi per usahatani serta menganalisis faktor-faktor yang mempengaruhi biaya transaksi jagung hibrida pipilan kering di provinsi Gorontalo.

\section{METODE PENELITIAN}

\section{Lokasi dan Waktu Penelitian}

Lokasi penelitian ditentukan secara purposive di Propinsi Gorontalo dengan fokus wilayah pada sentra-sentra produksi jagung hibrida pada dua kabupaten yaitu Kabupaten Gorontalo dan Kabupaten Boalemo. Penelitian dilakukan pada bulan November 2013 sampai Maret 2014.

\section{Metode Pengumpulan Data}

Jenis data yang digunakan adalah data primer yaitu dengan menggunakan kuisioner dengan responden petani jagung hibrida sebanyak 306 responden serta survey ke unit-unit UPJ mitra untuk memperoleh besaran biaya transaksi masing-masing petani. Selain itu penelitian ini menggunakan data sekunder dari Dinas Pertanian dan Badan Pusat Statistik (BPS) kebupaten Gorontalo dan kabupaten Boalemo.

\section{Analisis Data}

Metode analisis data yang digunakan meliputi perhitungan biaya transaksi penjualan jagung hibrida pipilan kering dan analisis faktor-faktor yang mempengaruhi biaya transaksi penjualan jagung hibrida pipilan kering melalui UPJ.

\section{Perhitungan biaya transaksi rata-rata:}

$\mathrm{TC}_{\mathrm{tr}}=\sum \mathrm{C}_{\mathrm{UTT}}+\mathrm{C}_{\mathrm{KD}}+\mathrm{C}_{\mathrm{R}}+\mathrm{C}_{\mathrm{D}}$

Keterangan:

$\mathrm{TC}_{\mathrm{tr}}=$ Total biaya transaksi usahatani jagung pipilan kering ( $\mathrm{Rp} /$ Transaksi);

$\mathrm{C}_{\mathrm{UTT}}=$ Upah tenaga teknis pihak UPJ (Rp/Transaksi);

$\mathrm{C}_{\mathrm{KD}}=$ Komisi distributor pihak UPJ (Rp/Transaksi);

$\mathrm{C}_{\mathrm{R}}=$ Nilai reduksi produk (Rp/Transaksi);

$\mathrm{C}_{\mathrm{D}}=$ Nilai degradasi produk (Rp/Transaksi).

Faktor-faktor yang mempengaruhi total biaya transaksi:

$$
\begin{aligned}
\mathrm{TC}_{\mathrm{tr}}= & \alpha+\beta_{1} \operatorname{LnX}_{1}+\beta_{2} \operatorname{LnX}_{2}+\beta_{3} \operatorname{LnX}_{3}+ \\
& \beta_{4} \operatorname{LnX}_{4}+\beta_{5} \operatorname{LnX} X_{5}+\beta_{6} \operatorname{LnX}_{6}+\beta_{7} \operatorname{LnX}_{7} \\
& +\beta_{8} \operatorname{LnX}_{8}+\beta_{9} \operatorname{LnX}_{9}+\beta_{10} \operatorname{LnX}_{10}+ \\
& \delta_{1} \operatorname{lnD}_{1}+\delta_{2} \operatorname{lnD}_{2}+\delta_{3} \operatorname{lnD}_{3}+\mu
\end{aligned}
$$

Keterangan:

$\mathrm{C}_{\mathrm{tr}}=$ total biaya transaksi usahatani jagung pipilan kering (Rp/transaksi);

$\alpha=$ intersep atau konstanta;

$\beta_{\mathrm{i}}=$ koefisien parameter variabel ke-i $(\mathrm{i}=1$ $\mathrm{s} / \mathrm{d} 10)$;

$\delta_{\mathrm{i}}=$ koefisien parameter variabel dummy ke-i (i= $1 \mathrm{~s} / \mathrm{d} 3)$;

$\mathrm{X}_{1}=$ jumlah total produksi jagung pipilan kering $(\mathrm{Kg})$;

$\mathrm{X}_{2}=$ harga pasar regional $(\mathrm{Rp})$;

$\mathrm{X}_{3}=$ upah tenaga teknis (Rp/Transaksi);

$\mathrm{X}_{4}=\operatorname{komisi}(\mathrm{Rp} /$ Transaksi);

$\mathrm{X}_{5}=$ nilai reduksi (Rp/Transaksi);

$\mathrm{X}_{6}=$ nilai degradasi (Rp/Transaksi);

$\mathrm{X}_{7}=$ umur (tahun);

$\mathrm{X}_{8}=$ pendidikan (tahun);

$\mathrm{X}_{9}=$ frekuensi Bimbingan (Kali);

$\mathrm{X}_{10}=$ jarak rumah - UPJ $(\mathrm{Km})$;

Dummy pengalaman usahatani:

$\mathrm{D}_{1}=1$ jika pengalaman usahatani $\geq 3$ tahun, $\mathrm{D}_{1}=0$ jika $<3$ tahun;

Dummy kelembagaan modal:

$\mathrm{D}_{2}=1$ jika memanfaatkan kelembagaan modal, $\mathrm{D}_{2}=0$ jika tidak. 
Dummy gender:

$\mathrm{D}_{3}=1$ jika kepala keluarga laki-laki, $\mathrm{D}_{3}=0$ jika perempuan;

$\boldsymbol{\mu}=$ error term.

Nilai koefisien parameter yang diharapkan yaitu: $\beta_{3}, \beta_{4}, \beta_{5}, \beta_{6}>0$

\section{HASIL DAN PEMBAHASAN}

\section{Perhitungan Total Biaya Transaksi Jagung Hibrida Pipilan Kering Di Provinsi Gorontalo}

Total biaya transaksi merupakan jumlah total rata-rata biaya transaksi penjualan yang meliputi upah tenaga teknis, komisi distributor, biaya reduksi, biaya degradasi, sewa kontrak lapak, upahtenaga kerja pemeliharaan properti, dan sewa transportasi per usahatani.

\section{Upah tenaga teknis}

Upah tenaga teknis merupakan bagian dari biaya transaksi yang merupakan bagian dari biaya informasi yaitu pada sub kategori biaya pengembangan. Biaya pengembangan dimaksud merupakan biaya yang dikeluarkan sebelum adanya transaksi untuk memperkiraan, menentukan dan memastikan suatu permasalahan sebelum dilakukan pelaksanaan transaksi. Menurut Hobbs (1997) dan Tanyeri (2005) menggolongkan biaya informasi sebagai biaya pencarian informasi baik yang bersifat formal maupun tidak formal. Sedangkan upah tenaga teknis dimaksud merupakan biaya formal yang dikeluarkan petani melalui pembayaran tidak langsung melalui pihak UPJ yang nantinya akan mengurangi pendapatan atas penjualan jagung pipilan kering oleh petani dari pemotongan biaya transaksi oleh pihak UPJ. Rata-rata upah tenaga teknis pada usahatani jagung hibrida sebesar Rp 301.132 per transaksi per usahatani.

\section{Komisi}

Biaya komisi merupakan bagian dari biaya yang ditanggung oleh petani pada saat transaksi berlangsung. Biaya komisi sebagai biaya administrasi distributor (UPJ) secara kelembagaan merupakan biaya transaksi yang terjadi pada saat pelaksanaan kontrak berlangsung. Collins dan Fabozzi (1991) dalam
Yustika (2013) menjelaskan bahwa komisi merupakan bentuk biaya transaksi yang bersifat biaya tetap. Sedangkan Strassman (2002) dalam Yustika (2013) menjelaskan bahwa biaya administratif merupakan biaya transaksi yang digolongkan ke dalam biaya penjualan, umum dan administratif. Biaya komisi yang dikenakan oleh masing-masing pihak UPJ cukup bervariasi mulai dari Rp100.000,- hingga Rp.300.000,- per transaksi per usahatani, sehingga biaya komisi rata-rata pada penjualan jagung hibrida pipilan kering sebesar $\mathrm{Rp}$ 204.710,- per transaksi per usahatani.

\section{Biaya reduksi}

Pada saat dilakukan pengangkutan dari tempat tinggal petani menuju gudang UPJ, maka terjadi reduksi sehingga mendepresiasi kuantitas total jumlah produk jagung pipilan kering. Reduksi ini disebabkan oleh faktor kondisional sarana jalan yang kurang baik sehingga menyebabkan sebagian kecil terjadi reduksi produk jagung pipilan kering. Menurut D'Hondt dan Giraud (2008) bahwa tipologi biaya transaksi adalah biaya transaksi eksplisit dan biaya transaksi implisit tidak langsung atas kemungkinan terjadinya risiko pada saat proses transaksi. Hilangnya produk atas aktivitas pengangkutan di anggap sebagai risiko penjualan yang sering terjadi sehingga nilai atas kehilangan produk tersebut di kategorikan sebagai biaya transaksi eksplisit tidak langsung. Menurut pernyataan beberapa pihak UPJ ratarata reduksi produk pada usahatani jagung pipilan kering sebesar 20 hingga 60 kilogram, sehingga hal ini mengurangi jumlah volume penjualan jagung hibrida pipilan kering petani ke UPJ. Total nilai reduksi rata-rata yang terjadi pada pengangkutannya sebesar Rp158.903,- per transaksi per usahatani.

\section{Biaya degradasi}

Biaya degradasi merupakan biaya yang terjadi secara implisit atas kerugian yang diperoleh patani jagung hibrida pipilan kering atas terdegradasinya sebagian volume produk jagung pipilan kering. Menurut D'Hondt dan Giraud (2008) biaya degradasi dapat di kategorikan dalam biaya oportunitas penjualan yaitu biaya dari suatu produk adanya alternatif 
Mad Alfin A. M., Dwidjono H. D., Soeratno, Slamet H. : Analisis biaya transaksi ...

Tabel 1. Biaya Transaksi Rata-Rata Usahatani Jagung Hibrida Pipilan Kering Di Provinsi Gorontalo, 2014

\begin{tabular}{lll}
\hline Uraian & Satuan & Jumlah \\
\hline Upah Tenaga Teknis & Rp/Transaksi/Usahatani & 301.132 \\
Komisi & Rp/Transaksi/Usahatani & 204.710 \\
Nilai Reduksi & Rp/Transaksi/Usahatani & 158.903 \\
Nilai Degradasi & Rp/Transaksi/Usahatani & 878.656 \\
Total Biaya & Rp/Transaksi/Usahatani & 1.545 .466 \\
\hline Sumber: Analisis Data Primer $($ diolah)
\end{tabular}

Sumber: Analisis Data Primer (diolah)

yang hilang atas kegiatan menjual produk tersebut, dimana dalam hal ini dapat di tinjau melalui sisi kesalahan dalam menjual. Biaya degradasi muncul atas kesalahan petani dalam menentukan kadar air dari jagung hibrida sehingga menimbulkan biaya degradasi atas produk dengan kadar airnya di luar batas standar maksimal yang di tentukan oleh pihak UPJ (17 - 19 persen). Dari data yang diperoleh biaya degradasi rata-rata pada penjualan jagung hibrida pipilan kering adalah sebesar Rp 878.656,- per transaksi per usahatani.

Faktor-faktor yang mempengaruhi total biaya transaksi penjualan jagung hibrida pipilan kering

Dari hasil model regresi biaya transaksi diperoleh nilai konstanta signifikan untuk yang mengindikasikan bahwa variasi variabel independen dalam model cukup menjelaskan variasi variabel dependen total biaya transaksi. Selanjutnya dilakukan analisis pengaruh variabel independen terhadap variabel dependen biaya transaksi.

\section{Variabel total produksi}

Variabel total produksi merupakan total produksi jagung pipilan kering pada satu masa panen, memiliki berpengaruh secara negatif dan signifikan sebesar $-0,588$ yang menunjukkan bahwa kenaikan total produksi masing-masing sebesar 10 persen menurunkan total biaya transaksi penjualan jagung pipilan kering sebesar 5,88 persen. Hal ini merupakan indikasi bahwa semakin tinggi produksi yang dihasilkan oleh petani maka semakin menurun pembebanan biaya transaksi per unit yang ditanggung oleh petani tersebut secara agregatnya.

\section{Harga pasar regional}

Harga pasar regional merupakan harga pasar jagung pipilan kering regional di provinsi Gorontalo memiliki koefisien negatif dengan pengaruh nyata sebesar -0,192 yang menunjukkan bahwa kenaikan harga pasar regional jagung pipilan kering sebesar 10 persen akan berimbas pada turunnya total biaya transaksi sebesar 1,92 persen. Hal ini merupakan dampak atas naiknya pendapatan jagung pipilan kering sehingga mampu menutupi biaya transaksi secara tidak langsung.

\section{Upah tenaga teknis}

Upah tenaga teknis dan komisi distributor masing-masing sebesar 0,378 yang menunjukkan bahwa dengan adanya peningkatan 10 persen upah tenaga teknis akan meningkatkan total biaya transaksi sebesar 3,78 persen.

\section{Komisi}

Komisi distributor memiliki nilai koefisien sebesar 0,522 menunjukkan bahwa kenaikan total biaya transaksi sebesar 5,22 persen merupakan dampak atas kenaikan 10 persen komisi distributor. Hal ini mengindikasikan bahwa semakin tinggi tingkat persentase biaya komisi yang ditetapkan maka semakin tinggi pula biaya transaksi yang di tanggun petani yang menjual jagung pipila keringnya melalui UPJ.

\section{Biaya Degradasi}

Nilai degradasi memiliki koefisien sebesar 0,500 yang menunjukkan bahwa dengan adanya kenaikan 10 persen nilai degradasi produk jagung pipilan kering akan meningkatkan total biaya transaksi sebesar 5 persen. 
Tabel 2. Regresi Modal Biaya Transaksi Penjualan Jagung Pipilan Kering Di Provinsi Gorontalo, 2014

\begin{tabular}{llll}
\hline Variabel & Tanda Harapan & Koefisien & Prob. \\
\hline Konstanta & $+/-$ & $\left.-4.326^{*}\right)$ & 0.0000 \\
Total Produksi & $+/-$ & $\left.-0.588^{*}\right)$ & 0.0000 \\
Harga Pasar Regional & $+/-$ & $\left.0.192^{*}\right)$ & 0.0004 \\
Upah Tenaga Teknis & + & $\left.0.378^{*}\right)$ & 0.0000 \\
Komisi & + & $\left.0.522^{*}\right)$ & 0.0022 \\
Nilai Reduksi & + & $0.164^{\text {ns }}$ & 0.0633 \\
Nilai Degradasi & + & $\left.0.500^{*}\right)$ & 0.0208 \\
Umur & $+/-$ & $0.027^{\text {ns }}$ & 0.5745 \\
Pendidikan & $+/-$ & $-0.042^{\text {ns }}$ & 0.1223 \\
Frekuensi Bimbingan & $+/-$ & $\left.0.064^{*}\right)$ & 0.0034 \\
Jarak Rumah - UPJ & $+/-$ & $0.006^{\text {ns }}$ & 0.8200 \\
Dummy Pengalaman Usahatani & $+/-$ & $0.0008^{\text {ns }}$ & 0.9827 \\
Dummy Kelembagaan Modal & $+/-$ & $0.006^{\text {ns }}$ & 0.7502 \\
Dummy Gender & $+/-$ & $0.003^{\text {ns }}$ & 0.8277 \\
Adj.R squared & & 0,978 & \\
F-statistik & & 1077,206 & \\
Prob(F-statistik) & & 0,000 & \\
\hline Keterangan: ${ }^{*}$ - signifikan & & & \\
\hline
\end{tabular}

Keterangan: ${ }^{*}=$ signifikan pada $\alpha ; 5 \%$;ns = tidak signifikan

Sumber: Analisis Data Primer (diolah)

\section{Variabel karakteristik frekuensi bimbingan}

Untuk faktor frekuensi bimbingan memiliki pengaruh positif dengan respon signifikan pada model biaya transaksi penjualan jagung pipilan kering sebesar 0,5 yang menunjukkan bahwa kenaikan 10 persen frekuensi bimbingan akan meningkatkan biaya transaksi penjualan jagung pipilan kering sebesar 5 persen. Hal ini disebabkan oleh kecenderungan perilaku penyuluh yang mendorong petani untuk menjual jagung hibrida melalui UPJ dengan harapan adanya efisiensi biaya dan waktu pemasaran.

\section{KESIMPULAN DAN IMPLIKASI KEBIJAKAN}

\section{Kesimpulan}

a. Total biaya transaksi rata-rata pada usahatani jagung hibrida pipilan kering melalui penjualan ke UPJ masih cukup tinggi sebesar Rp1.545.466,- per transaksi per usahatani sehingga berdampak pada rendahnya pendapatan usahatani.

b. Faktor-faktor yang mempengaruhi secara signifikan terhadap biaya transaksi penjualan jagung pipilan kering melalui UPJ meliputi total produksi, harga pasar regional, upah tenaga teknis, komisi dan nilai degradasi.

\section{Implikasi Kebijakan}

a. Perlu adanya revitalisasi kelembagaan unit usaha menuju kelembagaan berbasis usaha rakyat berupa pendayagunaan koperasi petani dalam aktivitas distribusi jagung hibrida pipilan kering kepada konsumen;

b. Perlu adanya kebijakan standarisasi biaya transaksi dari pemerintah daerah setempat guna menunjang kelangsungan usahatani jagung hibrida di provinsi Gorontalo.

\section{DAFTAR PUSTAKA}

Aubert, Benoit A. and Weber, Ron. 2001. "Transaction Cost Theory, The Resource-Based View and Information Technology Sourcing Decision: A ReExamination of Lacity Et Al 'S Findings". Paper, University of Queensland.

Badan Pusat Statistik Kabupaten Boalemo. 2013. Kabupaten Boalemo Dalam Angka 2013. Dipublikasikan.

Badan Pusat Statistik Kabupaten Gorontalo. 2013. Kabupaten Gorontalo Dalam Angka 2013. Dipublikasikan. 
Ghatak, Subrata and Ingersent, Ken, 1984, Agriculture and Economic Development. Harvester Press Publishing Group: Britain.

Hayami, Y and V.W, Rutan. 1985. Agricultural Development: An International Respective. The John Hopkins Press. Baltimore: London.

Hobbs, Jill E. 1997. Measuring The Importance of Transaction Costs in Cattle Marketing. American Journal Agricultural Economics, American Agricultural Economics Association, pp. 1083-1095.

Minot, Nicholas. 1999. Effect of Transaction Costs on Supply Response and Marketed Surplus: Simulations Using NonSeperable Household Models. MSSD
Discussion Paper, No. 36. International Food Policy Research Institute. Washington D.C: USA.

Nicholas, Stephen. 1987. Emperical Tests of the Transaction Cost Model: The Evolution of the Pre-1939 British Manufacturing Multinational. Business and Economic History, 2th series, Vol. 16th.

North, Doughlass C. 2012. Transaction Cost: Cost Model -Identify, Analyze, Quantify. Discussion Paper, Northfield, www.northinfo.com.

Yustika, Ahmad Erani. 2013. Ekonomi Kelembagaan Paradigma, Teori dan Kebijakan. Erlangga: Jakarta. 